\title{
Analysis of the Acid and Alkali Resistance of Superhydrophobic Paper Mulch
}

Fangyuan Zhang

Gansu Agricultural University

Anling Li ( $D$ lal@ayit.edu.cn )

Gansu Agricultural University https://orcid.org/0000-0002-9426-9830

\section{Wuyun Zhao}

Gansu Agricultural University

\section{Research Article}

Keywords: Superhydrophobic, Paper mulch, Mechanical property, Acid-base resistance property, Highspeed bounce behavior

Posted Date: February 25th, 2021

DOI: https://doi.org/10.21203/rs.3.rs-240655/v1

License: (9) This work is licensed under a Creative Commons Attribution 4.0 International License. Read Full License

Version of Record: A version of this preprint was published at Cellulose on July 11th, 2021. See the published version at https://doi.org/10.1007/s10570-021-04065-5. 


\section{Abstract}

The paper mulch will inevitably suffer the influence of the acidic or alkaline environment during the usage. To evaluate the influence of the acidic or alkaline environment on the corrosion resistance of the paper film, we investigate the method of immersing the paper film with acid and alkali solution. We use the hydrophobic $\mathrm{SiO}_{2}$ to prepare a superhydrophobic paper mulch with a contact angle of $155^{\circ}$ with water. Two kinds of superhydrophobic paper mulch were put into $\mathrm{H}_{2} \mathrm{SO}_{4}$ solution with $\mathrm{pH} 4.6$ and $\mathrm{NaOH}$ solution with $\mathrm{pH} 8.5$, respectively. After soaking for $48 \mathrm{~h}$, we use a contact angle tester, a tensile testing machine, and a high-speed camera to compare the contact angle, mechanical properties, and bounce performance of these two paper mulches. The results showed that the tensile strength and droplet bounce height of the superhydrophobic paper mulch decreased after being soaked in the acid or alkaline solution for 48 hours. The mass-loss rate of the paper mulch in acid solution is more significant, and its contact angle is still greater than $145^{\circ}$ which treats as a good bounce performance. The microscopic morphology of the paper showed that $\mathrm{SiO}_{2}$ can form a superhydrophobic structure on the surface of the paper mulch. The method is simple and environmentally friendly and can solve the problem of poor acid and alkali corrosion resistance of the paper mulch. It has extraordinary significance in reducing the environmental pollution.

\section{Introduction}

Paper mulch is made of plant fiber, which is essentially different from traditional plastic mulch in composition. Since plant fiber can be degraded by microorganisms, it does not need to be recycled after use and has almost no side effects on the environment ${ }^{[1-3]}$. However, there are still some problems in the actual application of paper mulch. Because the fiber contains a large number of hydroxyl groups, it is a hydrophilic material and will absorb water and expand in a humid environment, destroying its mechanical properties and durability ${ }^{[4-5]}$. Because of the exposure in the harsh outdoor environment for a long time, the paper mulch needs to have good durability. In both of the slightly acidic and alkaline soil and under the erosion of rain, it can still provide heat preservation and moisturizing living environment for plants ${ }^{[6-}$ 7].

Many plants and insects in nature have the superhydrophobic structures. For example, the upper surface of the lotus leaf has a pointed dome-shaped papillary structure, which can make water droplets roll freely on the surface without wetting the lotus leaf. This is also called the "lotus leaf effect". The microscopic surface of rose petals is composed of a certain periodic array of papillary structures and nano-scale folds, which makes rose petals with low adhesion and superhydrophobic properties [9]. The feet of water flies have bristles that are $20^{\circ}$ and in the same direction of the foot surface, and there are nano-scale lines on the bristles. This structure allows the water flies to crawl freely on the water surface without falling to the water [10,11]. The surfaces of these plants and animals have a special superhydrophobic structure, and the contact angle with water can reach more than $150^{\circ}$. If the surface of the paper is given a superhydrophobic structure, it can effectively resist the penetration of moisture into its internal structure, and 
its durability can be improved to a certain extent. There are many ways to prepare superhydrophobic properties, including chemical graft modification [12], surface coating [13,14], electrospinning [15,16], solgel method [17,18], corrosion Method [19,20], template method [21], solution immersion method [22], etc.

Using powder particles to make a low surface energy coating on the surface of the paper is a relatively simple way to change the superhydrophobic properties of paper mulch. The materials that have been reported are four-pin type $\mathrm{ZnO}$ [23], $\mathrm{SiO}_{2}$ [24], $\mathrm{CeO}_{2}$ [25], and so on. The fibers in the paper mulch will be corroded in an acidic or alkaline environment [26-27], and the surface is covered with a layer of low surface energy material, which can make the paper mulch achieve the super-hydrophobic effect. However, it also produce certain protection to enhance the corrosion resistance of the paper mulch in acidic or alkaline environments.

In order to make the hydrophobic surface of the paper mulch and the resistance to acids and alkalis, we adopted a simple and easy-to-implement solution immersion method while reducing the cost. A hydrophobic $\mathrm{SiO}_{2}$ is attached to the surface of the paper mulch to prepare a acid and alkali-resistant paper mulch that also has a good hydrophobicity and protect the fibers in the paper mulch.

\section{Experimental Procedure}

\subsection{Materials}

The fully degradable paper base film (hereinafter referred to as paper mulch) was purchased from Shandong Rebos Tobacco Co., Ltd. (China). HB-139 hydrophobic SiO2 was provided through Hubei Yichang Huifu Silicon Material Co., Ltd. (China). Anhydrous ethanol was supplied from Tianjin Fuyu Fine Chemical Co., Ltd. (China). KH550 coupling agent was supplied from Qufu Chenguang Chemical Co., Ltd. (China). Homemade distilled water in the laboratory. $\mathrm{H}_{2} \mathrm{SO}_{4}$ solution. $\mathrm{NaOH}$ solution.

\subsection{Main experimental equipment and instruments}

The NANO SEM450 scanning electron microscope was purchased from NOVA Co., Ltd. (USA). The SMT5000 electronic universal testing machine was purchased from Yangzhou Saisi Testing Equipment Co., Ltd. (China). The FA3104N electronic analytical balance was purchased from Shanghai Jinghai Instrument Co., Ltd. (China). The FE28 pH meter was purchased from METTLER TOLEDO Instruments Co., Ltd. (China). HKCA-15 contact angle tester was purchased from Beijing Harco Experimental Instrument Factory (China). DHG-9070A blast drying oven was purchased from Shanghai Heng Science Instrument Co., Ltd. (China). Interferometric three-dimensional surface topography instrument (ZeGage type, ZYGO, USA). High-speed camera (NAC MEMRECAM HX-6E, Japan). Fourier infrared spectrometer (FTIR, IRTracer-100, Japan).

\subsection{Experimental preparation process}


Figure 1 shows the sample preparation process. Firstly, we add $1.5 \mathrm{~g}$ of $\mathrm{SiO}_{2}$ powder to $100 \mathrm{ml}$ of absolute ethanol, and sonicate it for $10 \mathrm{~min}$ to make the $\mathrm{SiO}_{2}$ powder dispersed uniformly. Then $0.15 \mathrm{~g}$ of coupling agent (KH550) was added, and sonicate for 10 min. Finally, the paper mulch was immersed in the prepared $\mathrm{SiO}_{2}$ solution, and it was taken out after standing for $1 \mathrm{~min}$ and placed in a high-temperature drying oven at the temperature of $35^{\circ} \mathrm{C}$ for 10 min to obtain $\mathrm{SiO}_{2}$ /superhydrophobic paper mulch samples.

The acid and alkali resistance test mainly use the $\mathrm{H}_{2} \mathrm{SO}_{4}$ solution $(\mathrm{pH}=4.6)$ and $\mathrm{NaOH}$ solution $(\mathrm{pH}=8.5)$ to simulate acidic and alkaline environments. The paper mulch was soaked in $\mathrm{H}_{2} \mathrm{SO}_{4}$ solution with $24 \mathrm{~h}$ as a gradient, and $24 \mathrm{~h}, 48 \mathrm{~h}$, and $0 \mathrm{~h}$ controls were set, respectively. After the soaking is complete, put the paper mulch in a drying oven at the temperature of $35^{\circ} \mathrm{C}$ and dry for 10 minutes, and take out the sample for other performance tests.

The sample numbers of the paper mulch are as follows (the sample names of the paper mulch are abbreviated as the number names):

Table.1 Sample number

\begin{tabular}{|lllll|}
\hline Sample & $\begin{array}{l}\mathrm{pH} 4.6 \mathrm{SiO}_{2} / \text { paper } \\
\text { mulch }\end{array}$ & $\begin{array}{l}\mathrm{pH} 4.6 \text { paper } \\
\text { mulch }\end{array}$ & $\begin{array}{l}\mathrm{pH} 8.5 \mathrm{SiO}_{2} / \text { paper } \\
\text { mulch }\end{array}$ & $\begin{array}{l}\mathrm{pH} 8.5 \text { paper } \\
\text { mulch }\end{array}$ \\
Num. & $4.6 \mathrm{SPM}$ & $4.6 \mathrm{PM}$ & $8.5 \mathrm{SPM}$ & $8.5 \mathrm{PM}$ \\
\hline
\end{tabular}

\subsection{Performance testing and characterization}

Contact angle (CA): Cutting the paper mulch that has been processed in different ways into a $10 \mathrm{~mm} \times 20$ $\mathrm{mm}$ rectangle, we fix it on a glass slide with double-sided tape and measure the contact angle with a contact angle tester. Using the laboratory-made deionized water with a droplet size of $4 \mu \mathrm{L}$, six different points on the sample surface were selected for repeated experiments to reduce measurement errors.

Horizontal bounce test: to ensure the same size of droplets each time, the test uses the same needle, and the drop height is set to $10 \mathrm{~cm}$. A high-speed camera was used to photograph the process of droplets falling onto the surface of the paper mulch film and bouncing repeatedly which can be used to analyze the bounce behavior of the droplets on the paper mulch film.

SEM and EDS: The particle size and shape of the $\mathrm{SiO}_{2}$ powder and the three-dimensional morphology of the paper mulch surface were observed by scanning electron microscopy, and the surface structure of the superhydrophobic paper mulch was changed after silica was attached to the surface. The element distribution and content on the surface of the sample were analyzed by X-ray energy spectrum. By scanning the surface of the paper mulch soaked in acid or alkaline solution for $24 \mathrm{~h}$ and $48 \mathrm{~h}$, we can analyzed the hydrophobic properties and acid and alkali resistance properties of the paper mulch. 
Mass-loss ratio: Weigh the mass of the sample with an electronic balance before soaking. After immersing in acidic solution and alkaline solution for $24 \mathrm{~h}$ and $48 \mathrm{~h}$, the sample is dried in a hightemperature drying oven, and the mass of the sample is weighed again with an electronic balance. The data is based on the mass loss ratio of five repeated experiments. The average value (the ratio of mass loss is the ratio of the difference in quality to the original mass), and analyze the influence of the acidbase environment on the acid-base resistance of the sample.

Mechanical properties: The sample size and dimensions are shown in Fig.2. We use the electronic universal testing machine to test the tensile properties of the original paper mulch, the silica-treated paper mulch, and the samples soaked in the acid or alkaline solution for $24 \mathrm{~h}$ and $48 \mathrm{~h}$. The tensile rate is $100 \mathrm{~mm} / \mathrm{min} \pm 10 \mathrm{~mm} / \mathrm{min}$.

\section{Results And Discussion}

\section{$3.1 \mathrm{SiO}_{2}$ powder characterization}

Fig.3 (a) shows the $\mathrm{SiO}_{2}$ particles uniformly dispersed in the anhydrous ethanol solution. Fig.3 (b) is an enlarged view of one $\mathrm{SiO}_{2}$ particle with slightly larger size. The measured particle size is $6.758 \mu \mathrm{m}$, which is a loose and porous spherical structure. However, the spherical structure is beneficial to reduce the surface energy of the paper film surface, thereby it is hydrophobic. Fig.3 (c) shows the hydrophobic effect of silica powder. $\mathrm{NaOH}, \mathrm{H}_{2} \mathrm{SO}_{4}, \mathrm{NaCl}$, Distilled water $\left(\mathrm{D} \mathrm{H}_{2} \mathrm{O}\right)$, and Deionized water (DI) all have a large contact angle on the surface of silica, which proves that the dioxide Silicon powder has good hydrophobic property.

\subsection{Morphological characterization of paper mulch under different processing methods}

By observing Fig.4 (a) and (b), the fiber structure on the surface of the paper mulch is intertwined to form a network structure with a certain mechanical strength. The shape and outline of the fiber can be clearly observed. After further observation, it was found that the surface of the paper mulch was not smooth, and there are many gaps between the fibers. By zooming in, it was found that the width and length of the fiber are different. An interferometric three-dimensional profiler is used to measure the surface roughness of paper mulch. Fig.4 (c) is a three-dimensional cloud map of the surface roughness of the paper mulch. By calculating the average surface roughness, the arithmetic average height of $\mathrm{Sa}$ is $5.784 \mu \mathrm{m}$. The highest and lowest height difference (Sz) reached to $64.893 \mu \mathrm{m}$. Observing Fig.4 (d), it is found that the silica powder is evenly covered on the surface of the paper mulch. By Fig.4 (e), a part of the $\mathrm{SiO}_{2}$ powder is filled into the voids of the fibers on the surface of the paper mulch, and a part is covered on the fiber surface of the paper mulch. As shown in Fig.4 (f), the measured Sa of $\mathrm{SiO}_{2} /$ paper mulch is $6.637 \mu \mathrm{m}$. The $\mathrm{SiO}_{2} /$ paper mulch is compared with the untreated paper mulch. As the $\mathrm{SiO}_{2}$ powder is covered on the surface of the paper mulch, the roughness increases. 
We conducted an EDS analysis on the paper mulch. As shown in Fig.5, the surface elements of the

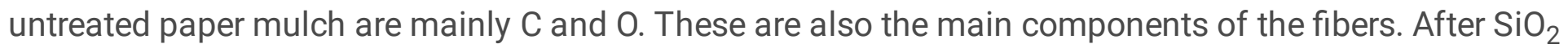
treatment, the percentage of the $\mathrm{C}$, and $\mathrm{O}$ on the surface of the paper mulch is reduced, and a small amount of $\mathrm{Si}$ element is added to the paper mulch which proves $\mathrm{SiO}_{2}$ has covered on the surface of the paper mulch.

Observing Fig.6 (a) and (b), it is found that part of the fiber structure was broken after the paper mulch was immersed in an acidic solution for 24 hours, and a small part of the fiber was corroded by acid. But the shape and contour of the fiber can still be identified. Therefore, the mechanical properties of the fiber are reduced. Compared with the unsoaked original paper mulch, the roughness of the paper mulch soaked in the acid solution for 24 hours has increased. The Sa of the original paper mulch soaked in $\mathrm{H}_{2} \mathrm{SO}_{4}$ with a pH of 4.6 for 24 hours was $6.641 \mu \mathrm{m}$. It can be seen from Fig.6 (c) that the measured Sa increased to $7.975 \mu \mathrm{m}$ after the paper mulch was immersed in the acidic solution for 48 hours. Observing Fig.6 (d), it is found that most of the fibers on the surface of the $\mathrm{SiO}_{2}$ /paper mulch have been corroded by the acid solution. Meanwhile some of the fibers are broken and fall off and the outline of the fibers has gradually blurred.

It can be seen from Fig.6 (e) that after the $\mathrm{SiO}_{2}$ treated paper mulch is soaked in an acidic solution for 24 hours, the $\mathrm{SiO}_{2}$ particles on the surface have a little shedding and a little dent is produced. Shown in Fig.6(f), the acidic solution has contacted the fibers and corroded the fibers, which increasing the roughness of the $\mathrm{SiO}_{2}$ /paper mulch. It can be seen from Fig.6 (g) and (h) that after 48 hours of $\mathrm{H}_{2} \mathrm{SO}_{4}$ soaking, due to the acid corrosion of the fiber, some of the raised $\mathrm{SiO}_{2}$ has fallen off.

As shown in the results of Fig.7 (a) and (b), it was found that the Si element on the surface of the $\mathrm{SiO}_{2} /$ paper mulch film soaked for $24 \mathrm{~h}$ was reduced. It is consistent with the result that the surface of the $\mathrm{SiO}_{2}$ /paper mulch covered by $\mathrm{SiO}_{2}$ particles has a little peeling off in the SEM image. Observing Fig.7 (c) and (d), it is found that the $\mathrm{Si}$ element content of the $\mathrm{SiO}_{2} /$ paper mulch surface immersed for $48 \mathrm{~h}$ is less than that after $24 \mathrm{~h}$. Part of the $\mathrm{SiO}_{2}$ has fallen off, but $\mathrm{SiO}_{2}$ still adheres to the $\mathrm{SiO}_{2} /$ paper mulch.

Fig.8 (a) showsthat after the original paper mulch (PM) is soaked in an alkaline solution for 24 hours, the surface fibers are deformed. This phenomenon reduces the mechanical strength of the paper mulch. Since the paper mulch did not break or fall off, the quality loss was not obvious. Comparing Fig.8 (b) and (c), it is found that the surface roughness of the paper mulch increases after being immersed in the alkaline solution for 48 hours. Observing Fig. 8 (d), it is found that part of the fiber structure has changed from a strip-like fiber structure to a sheet-like fiber structure. The result shows that the fiber structure has undergone significant corrosion. Observing Fig.8 (e), it is found that the fiber structure of the $\mathrm{SiO}_{2} /$ paper mulch has not changed significantly after being immersed in an alkaline environment for 24 hours. The reason for this result may be that $\mathrm{SiO}_{2}$ is an acidic oxide. At room temperature, $\mathrm{SiO}_{2}$ reacts slowly with $\mathrm{NaOH}$ to produce $\mathrm{Na}_{2} \mathrm{SiO}_{3}$ and $\mathrm{H}_{2} \mathrm{O}$. The $\mathrm{SiO}_{2}$ particles covered on the paper mulch can protect the fiber structure of the paper mulch. Comparing Figure $8(f)$ and $(g)$, it is found that the surface roughness of the 
paper mulch increased after being soaked for 48 hours. Also, it is found that the $\mathrm{Si}$ element on the surface of the $\mathrm{SiO}_{2}$ /paper mulch is reduced by Fig.8(h). It shows that the $\mathrm{SiO}_{2}$ particles on the surface of the $\mathrm{SiO}_{2} /$ paper mulch have fallen off.

By Fig.9, we find that the $\mathrm{Si}$ element on the surface of the $\mathrm{SiO}_{2} /$ paper mulch after immersing for 24 hours in an alkaline environment is less than immersing in an acidic environment for same period. After soaking in the alkaline solution for $48 \mathrm{~h}, \mathrm{SiO}_{2}$ was significantly reduced. The results showed that $\mathrm{SiO}_{2}$ and $\mathrm{NaOH}$ reacted when $\mathrm{SiO}_{2}$ /paper mulch was soaked in the alkaline solution. At the same time, a large number of $\mathrm{SiO}_{2}$ particles adhere to the surface of the $\mathrm{SiO}_{2} /$ paper mulch, and the surface is hydrophobic.

\subsection{Hydrophobic performance test}

According to the superhydrophobic surface wetting principle, it is known that the hydrophobic properties of a solid surface are directly related to its surface energy. $\mathrm{SiO}_{2}$ particles are attached to the surface of the $\mathrm{SiO}_{2}$ treated paper mulch, which reduces the surface energy of the paper mulch and makes it hydrophobic.

As shown in Fig.10 (a), the contact angle of the paper mulch after $\mathrm{SiO}_{2}$ soaking treatment is obviously large, increasing from $135.91^{\circ}$ to $160.61^{\circ}$. Due to the low surface energy of hydrophobic $\mathrm{SiO}_{2}$ itself, it is coated on the surface of the paper mulch to reduce the surface energy of the paper mulch and then make the paper mulch showing a super hydrophobic effect. After soaking in acidic and alkaline solutions, the contact angles of paper mulch and $\mathrm{SiO}_{2}$ /paper mulch show a downward trend. The 4.6 PM and 4.6 SPM after being immersed in acidic solution for 48 hours decreased by $14.94^{\circ}$ and $12.94^{\circ}$, respectively. The contact angles of 8.5 PM and 8.5 SPM after immersing in alkaline solution for 48 hours decreased by $22.06^{\circ}$ and $12.94^{\circ}$, respectively. By contrast, the contact angle decreased more after the immersion in alkaline solution than the immersion in acid solution. In addition, whether it was immersed in acidic or alkaline solutions for 48 hours, the contact angles of the SiO2 treated paper mulch are greater than $145^{\circ}$.

Fig.10 (b) shows the hydrophobic effect on the surface of the paper mulch under $\mathrm{NaOH}, \mathrm{H}_{2} \mathrm{SO}_{4}, \mathrm{NaCl}, \mathrm{D}$ $\mathrm{H}_{2} \mathrm{O}$, DI droplets, indicating that the $\mathrm{SiO}_{2}$ /paper mulch has good hydrophobic properties. Therefore, it can be seen that the $\mathrm{SiO}_{2}$ /paper mulch can maintain good hydrophobicity in both acidic and alkaline environments. $\mathrm{SiO}_{2} /$ paper mulch shows acid and alkali resistance.

Fig.11 (a) is the diagram of the bounce behavior of the $\mathrm{SiO}_{2}$ / paper mulch surface after different treatments. The droplet falls from a height of $10 \mathrm{~cm}$ and can bounce multiple times on the surface of the sample. Combined with Fig.11 (b), it is found that as the droplet bounces several times, the spread diameter gradually decreases. Because the droplet is in the Wenzel model when it encounters the paper mulch, it causes energy loss. A small part of the droplets remained on the surface of the paper mulch, causing a large loss of capacity when the droplets bounce. The silicon dioxide attached to the surface of the SiO2/paper mulch is corroded and peeled off after immersion in the acid solution or alkali solution 
thatmakes the surface of the $\mathrm{SiO}_{2}$ /paper mulch form a more complex structure and then the contact area between the droplet and the surface of the $\mathrm{SiO}_{2}$ /paper mulch cut back. Observe Fig.11 (c), the maximum bounce height of $\mathrm{SiO}_{2} /$ paper mulch is $3.2 \mathrm{~mm}$. The maximum bounce height of the $\mathrm{SiO}_{2} /$ paper mulch after being soaked in acidic solution for $24 \mathrm{~h}$ is $6.2 \mathrm{~mm}$. The maximum bounce height of the $\mathrm{SiO}_{2} /$ paper mulch after $48 \mathrm{~h}$ soaking in acid solution is $5.0 \mathrm{~mm}$. The maximum bounce height of the $\mathrm{SiO}_{2} /$ paper mulch after soaking in alkaline solution for $24 \mathrm{~h}$ is $6.3 \mathrm{~mm}$. The maximum bounce height of the $\mathrm{SiO}_{2} /$ paper mulch after being immersed in alkaline solution for $48 \mathrm{~h}$ is $4.1 \mathrm{~mm}$. Experiments show that after soaking in acid or alkaline solution, the bounce performance of the $\mathrm{SiO}_{2} /$ paper mulch is improved.

\subsection{The effect of $\mathrm{pH}$ on the quality of paper mulch}

Observing Fig.12 (a) and (b), the mass-loss rate of paper mulch and $\mathrm{SiO}_{2} /$ paper mulch in acid solution is rising. Comparing Fig.12 (a) and (b), it is found that the mass loss rate of paper mulch and $\mathrm{SiO}_{2}$ /paper mulch in acid solution is significant. After being soaked in an acidic environment for 48 hours, the massloss of both paper mulch and $\mathrm{SiO}_{2}$ /paper mulch reached more than $8 \%$. But immersed in the alkaline solution, the mass-loss rate basically keeps below $1.5 \%$. Because the paper mulch contains a lot of fibers, the 1,4- $\beta$-glycosidic bonds in the fibers are more sensitive to acid and will break in an acidic environment, causing a part of the paper mulch surface material to dissolve in the acid solution, and resulting in the quality of the paper mulch cut back [28]. However, when immersed in an alkaline solution, the quality loss of the paper mulch is mainly due to the reaction of silica particles with sodium hydroxide and the falling off of the sample surface.

\subsection{The effect of $\mathrm{pH}$ on the mechanical properties of paper mulch}

From Fig.13 (a) and (b), we find that as the soaking time increases, the mechanical properties of the paper mulch decrease. From Fig.13 (a), after the paper mulch is soaked in an acidic environment, the $\mathrm{SiO}_{2} /$ paper mulch (SPM) has mild higher tensile properties than the original paper mulch (PM), which may be since $\mathrm{SiO}_{2}$ has a certain effect on the surface of the paper mulch, the reinforcing effect. From Fig.13 (b), it can be seen that after immersion in an alkaline environment, the tensile properties of $\mathrm{SiO}_{2}$ /paper mulch (SPM) are much higher than that of original paper mulch (PM). This is mainly due to the slow reaction of $\mathrm{SiO}_{2}$ with sodium hydroxide. The paper mulch has a certain protective effect.

\section{Conclusion}

1. Using $\mathrm{SiO}_{2}$ to prepare super-hydrophobic paper mulch. Due to the low surface energy of hydrophobic $\mathrm{SiO}_{2}$, the contact angle of the paper mulch surface increases from $135.91^{\circ}$ to $160.61^{\circ}$. In the test of acid and alkali resistance, the contact angle drops by $7.17^{\circ}$ in acidic solution and drops by $5.77^{\circ}$ in alkaline solution after immersing for $24 \mathrm{~h}$; The contact angle drops by $10.81^{\circ}$ in acid solution and drops by $4.16^{\circ}$ in alkaline solution after immersing for $48 \mathrm{~h}$. The solution dropped by $4.16^{\circ}$. This is due to the long-term soaking that causes some among of the silica to fall off the surface of the 
paper mulch, but the contact angle of the paper mulch is still higher than $145^{\circ}$ after 48 hours of soaking, indicating that the paper mulch still has good hydrophobic properties.

2. Paper mulch has good acid and alkali resistance. After being soaked in the solution for $48 \mathrm{~h}$, the mass loss of $\mathrm{SiO}_{2}$ /paper mulch in acidic solution was reduced by $1.24 \%$ compared with the original paper mulch, and the mass loss in alkaline solution was reduced by $0.42 \%$, indicating that the $\mathrm{SiO}_{2} /$ paper mulch was in acid or the alkaline solution has a certain protective effect on the paper mulch. Interestingly, after 48 hours of soaking, the quality loss of paper mulch in acidic solution is much greater than that of paper mulch in alkaline solution. This is because the 1,4- $\beta$-glycosidic bond in the fiber structure is more sensitive to acid, and the reaction between silica and alkali protects the fiber structure to a certain extent. This phenomenon was also confirmed in the mechanical performance test. When immersed for 24 hours, the silica/paper mulch in acid solution decreased by $2.34 \mathrm{kN}$, and the $\mathrm{SiO}_{2} /$ paper mulch in alkaline solution decreased by $0.7 \mathrm{kN}$, indicating the fiber structure strength of the paper mulch in the solution is better than that of the paper mulch in the acid solution.

3. The paper mulch has a good bounce performance. The results of the bounce test show that the droplets of the paper mulch treated with silica can bounce multiple times. Interestingly, due to the corrosion of the surface of the silica/paper mulch by acidic and alkaline solutions, a more complex spatial structure is formed on the surface. Compared with the unsoaked $\mathrm{SiO}_{2} /$ paper mulch, the maximum spreading diameter and the maximum bounce height of the $\mathrm{SiO}_{2} /$ paper mulch after immersing in an acid or alkaline solution for 24 hours are increased. Although the maximum spreading diameter and the maximum bounce height are reduced after immersing for $48 \mathrm{~h}$, they are still higher than the unsoaked silica/paper mulch.

\section{Declarations}

\section{Disclosure statement}

Ethics Committee approval was obtained from the Institutional Ethics Committee of Anyang Institute of Technology to the commencement of the study. No potential conflict of interest was reported by the author(s).

\section{Funding}

This research project was supported by Special fund project for modern agricultural industrial technology system (CARS-14-1-28)

\section{References}

1. Zhang H, DeVetter LW, Scheenstra E, et al. Weed Pressure, Yield, and Adhesion of Soil-biodegradable Mulches with Pie Pumpkin (Cucurbita pepo). Hortscience, 2020, 55(7): 1014-1021. 
2. Yang Y, Li PW, Jiao J, et al. Renewable sourced biodegradable mulches and their environment impact. Scientia Horticulturae, 2020, 268.

3. Larkin RP. Effects of Selected Soil Amendments and Mulch Type on Soil Properties and Productivity in Organic Vegetable Production. Agronomy-Basel, 2020,10(6).

4. Subrahmaniyan Kasirajan, Mathieu Ngouajio. Polyethylene and biodegradable mulches for agricultural applications: a review. Agronomy for Sustainable Development, 2012,32(2):501-529.

5. Chen, Kuan-Ju,Marsh, Thomas L.,Tozer, Peter R., et al. Biotechnology to sustainability: Consumer preferences for food products grown on biodegradable mulches[J].Food Research International,2019,116:200-210.

6. Landuzzi A, Ghosh J. Improving functionality of polyolefin films through the use of additives. Journal of Plastic Film \& Sheeting,2003,19(3),173-187.

7. Kalisz A, Siwek P, Sulak K. Influence of spunbond degradable floating row covers on microclimate modification and yield of field cucumber. Spanish Journal of Agricultural Research,2018,16(2).

8. J. Ensikat, P. Ditsche-Kuru, C. Neinhuis, et al. Superhydrophobicity in perfection: the outstanding properties of the lotus leaf. Beilstein J. Nanotechnol, 2011, 2: 152-161.

9. Lin, Y. N. Zhang, J. M. Xi, et al. Petal effect: A superhydrophobic state with high adhesive force. Langmuir, 2008, 24: 4114-4119.

10. Dickinson. How to walk on water. Nature $₫ 2003 \llbracket 424(6949): 621-622$.

11. F.Gao囚L. Jiang. Water-repellent legs of water striders. Nature $2004 \llbracket 432: 36$.

12. Bongiovanni, S. Marchi, E. Zeno, A. Pollicino, R. R. Thomas, Colloids Surf. A, 2013, 418, 52-59.

13. Hejazi I, Seyfi J, Sadeghi G M M, Jafari S H, et al. Investigating the interrelationship of superhydrophobicity with surface morphology, topography and chemical composition in spraycoated polyurethane/silica nanocomposites [J]. Polymer, 2017, 128:108-18.

14. Li Y, Chen S, Wu M, Sun J. All spraying processes for the fabrication of Robust, self-healing, superhydrophobic coatings [J]. Adv Mater, 2014.26(20): 3344

15. Lee S, Kim B, Kim S H, et al. Superhydrophobic, Reversibly Elastic, Moldable, and Electrospun (SupREME) Fibers with Multimodal Functions: From Oil Absorbents to Local Drug Delivery Adjuvants[J]. Advanced Functional Materials, 2017, 27(37):1702310.

16. Song $Y$, Wang L. Preparation of a new superhydrophobic nanofiber film by electrospinning polystyrene mixed with ester modified silicone oil [J]. Journal of Applied polymer Science, 2014, 131(17): 40718-40726.

17. Xiang $H$, Zhang L, Wang Z, et al. Multifunctional polymethylsilsesquioxane(PMSQ) surfaces prepared by electrospinning at the sol-gel transition: superhyreophobicity, excellent solvent resistance, thermal stability and enhanced sound absorption property [J]. Journal of Colloid and Interface Science,2011,359(1): 296-303.

18. S Heinonen, E Huttunen-Saarivirta, JP Nikkanen, Antibacterial properties and chemical stability of superhydrophobic silver-containing surface produced by sol-gel route [J]. Colloids and Surfaces A- 
Physicochemical and Engineering Aspects, 2014, 453: 149-161.

19. Zhao H, Kwak J H, Zhang Z C, et al. Studying cellulose fiber structure by SEM, XRD, NMR and acid hydrolysis [J]. Carbohydrate Polymers, 2007, 68(2): 235-241.

20. B Balu, V Breedveld, D W Hess. Fabrication of "roll-off" and "sticky" superhydrophobic cellulose surfaces via plasma processing^]. Langmuir, 2008, 24(9): 4785-4790.

21. Wang, G F; Zhou, J; Wang, M M, et al. A superhydrophobic surface with aging resistance, excellent mechanical restorablity and droplet bounce properties. Soft Matter, 2020, 16(23):5514-5524.

22. Kong L, Chen X, Yu L, et al. Superhydrophobic Cuprous Oxide Nanostructures on Phosphor-Copper Meshes and Their Oil-Water Separation and Oil Spill Cleanup[J]. ACS Applied Materials \& Interfaces, $2015,7(4)$.

23. Zhou, $X Y$; Wang, G F; Wang, M M , et al. A simple preparation method for superhydrophobic surface on silicon rubber and its properties. Progress in Organic Coatings, 2020, 143.

24. Yuhong Teng, Baoying Shi, Jiawei Zhang, et al. Preparation of robust superhydrophobic paper by roll coating with modified micro/nano $\mathrm{SiO}_{2}$. Advance Publication, 2020.

25. Zhang C H, Li C, Si X Q, et al. Mechanical durable ceria superhydrophobic coating fabricated by simple hot-press sintering. Applied Surface Science, 2020, 529.

26. Yang CJ, Wang M, Yang Z, et al. Investigation of Effects of Acid, Alkali, and Salt Solutions on Fluorinated Superhydrophobic Surfaces. Langmuir, 2019,35(52), 17027-17036.

27. Li QM, Liu H, Zhang SD, et al. Superhydrophobic Electrically Conductive Paper for Ultrasensitive Strain Sensor with Excellent Anticorrosion and Self-Cleaning Property. ACS Applied Materials \& Interfaces, 2019,11(24), 21904-21914.

28. Bower S, Wickramasinghe R, Nagle $\mathrm{N} \mathrm{J}$, et al. Modeling sucrose hydrolysis in dilute sulfuric acid solutions at pretreatment conditions for lignocellulosic biomass[J]. Bioresour Technol, 2008, 99(15):7354-7362.

\section{Figures}




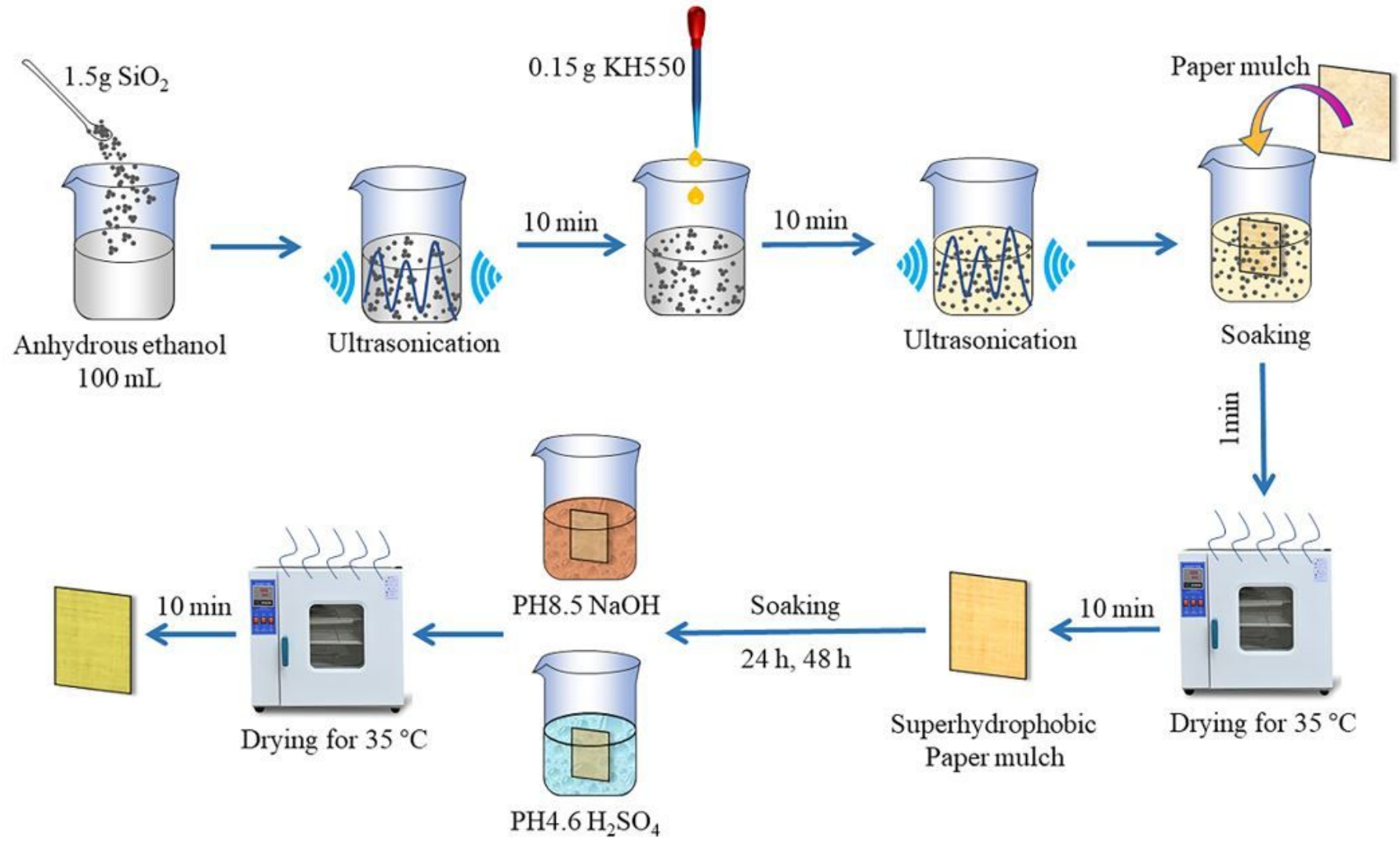

Figure 1

Superhydrophobic paper mulch sample preparation process

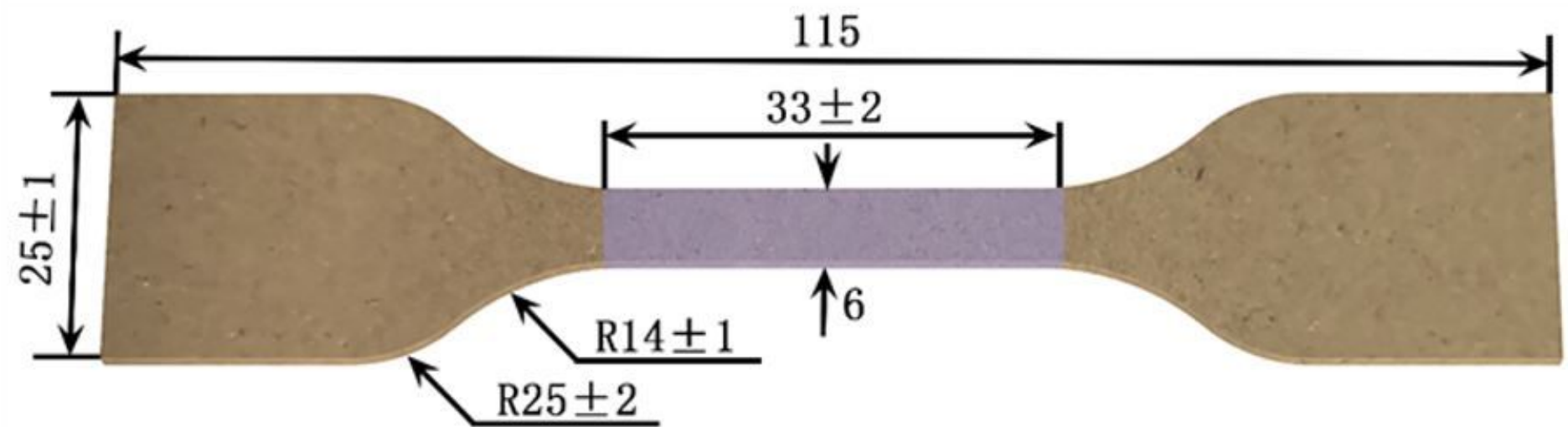

Figure 2

Tensile tear sample model 

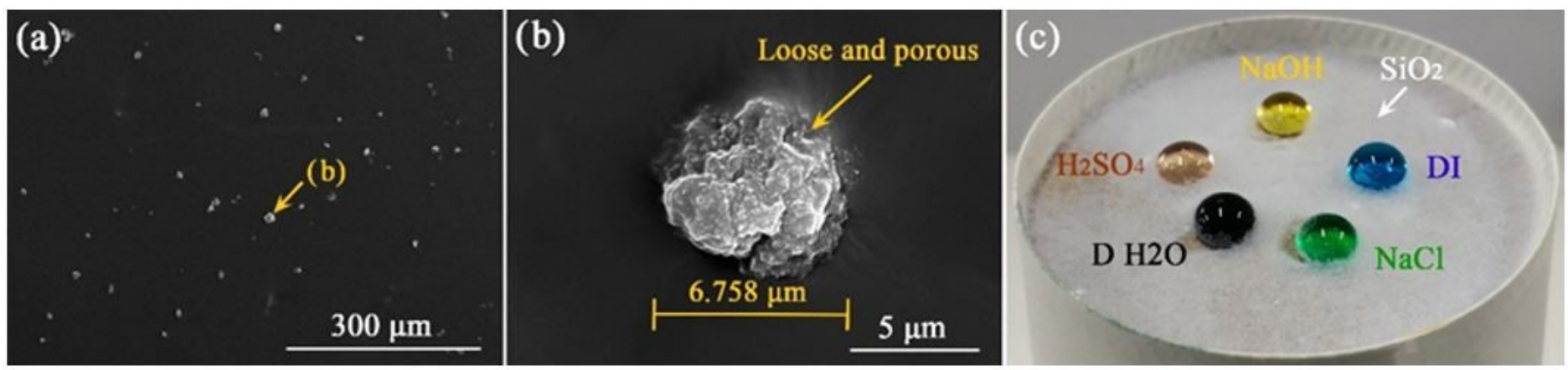

\section{Figure 3}

(a) is the SiO2 particles uniformly dispersed on the conductive adhesive. (B) is a SiO2 particle in (a). (c) The state of different droplets of acid, alkali, salt, etc. on the surface of SiO2 powder.
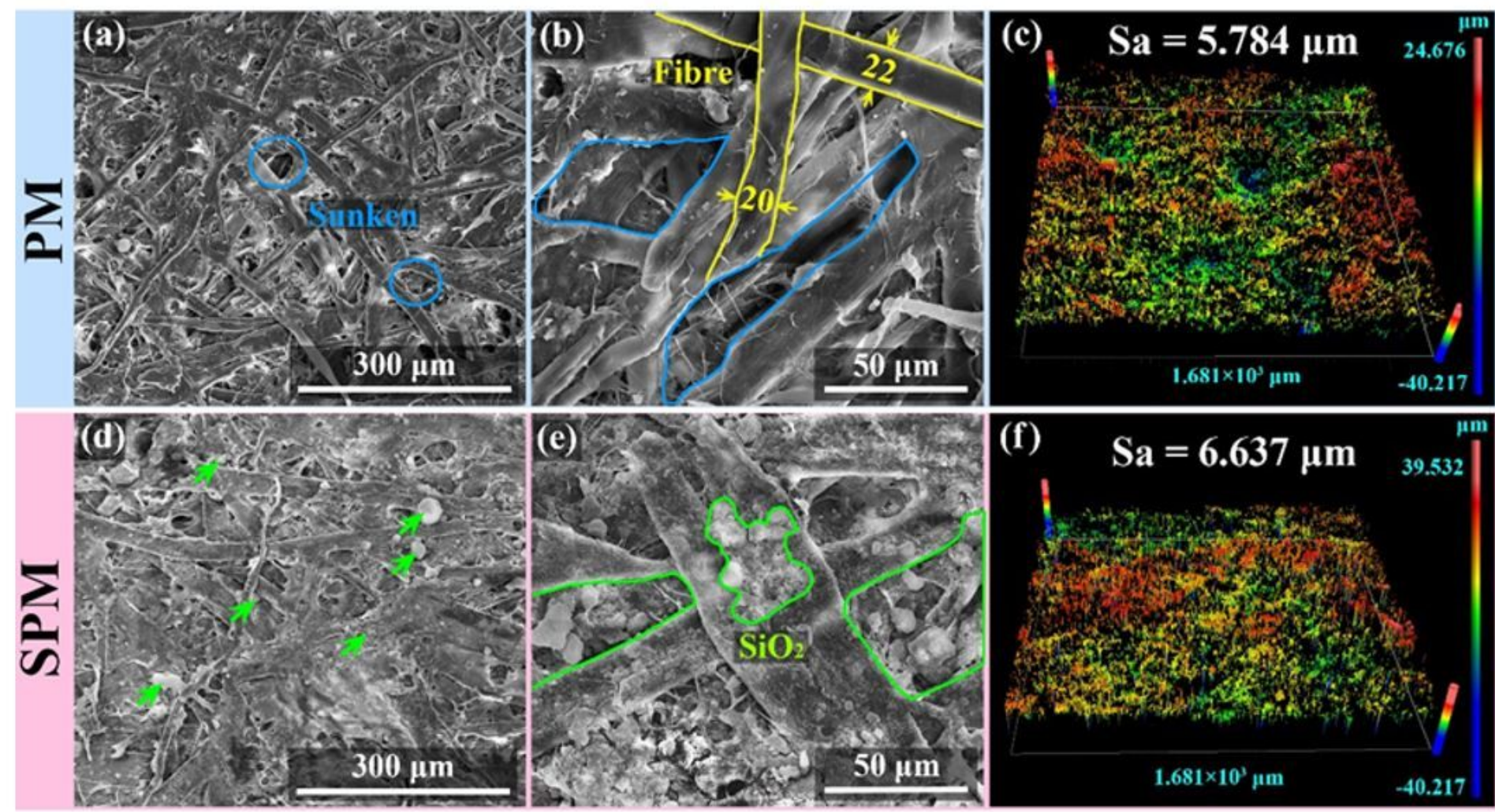

\section{Figure 4}

The SEM image of the surface of the original paper mulch (PM) (a) 500 times (b) 2000 times. (c) Surface roughness map of original paper mulch. SEM image of the surface of SiO2/paper mulch (SPM) (d) 500 times (e) 2000 times. (f) SiO2/paper mulch (SPM) surface roughness map 

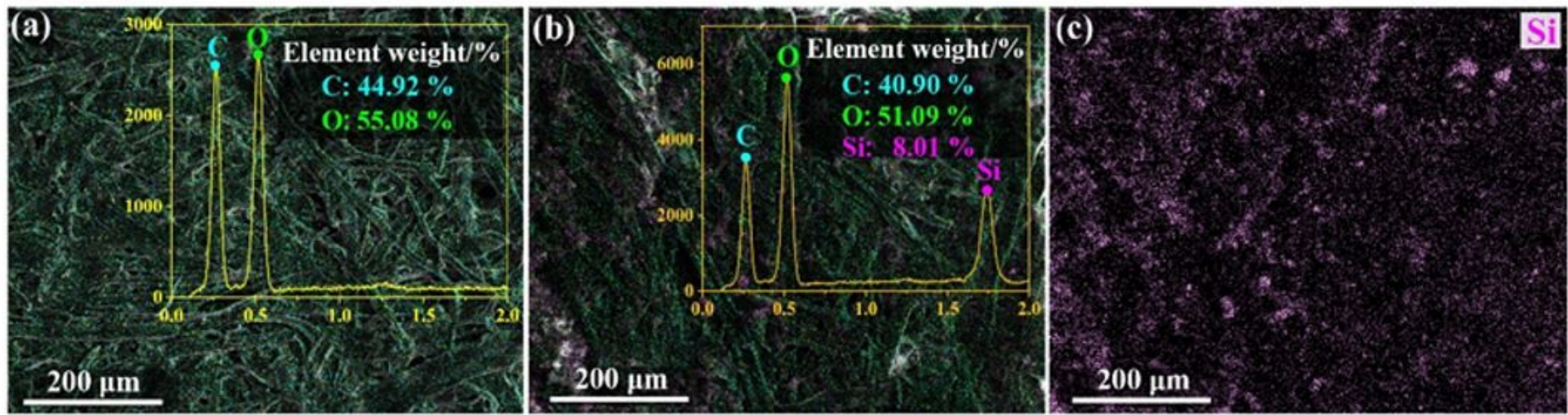

\section{Figure 5}

(a) EDS element analysis on the surface of paper mulch. SiO2/paper mulch surface, (b) EDS element distribution map, (c) Si element distribution map.

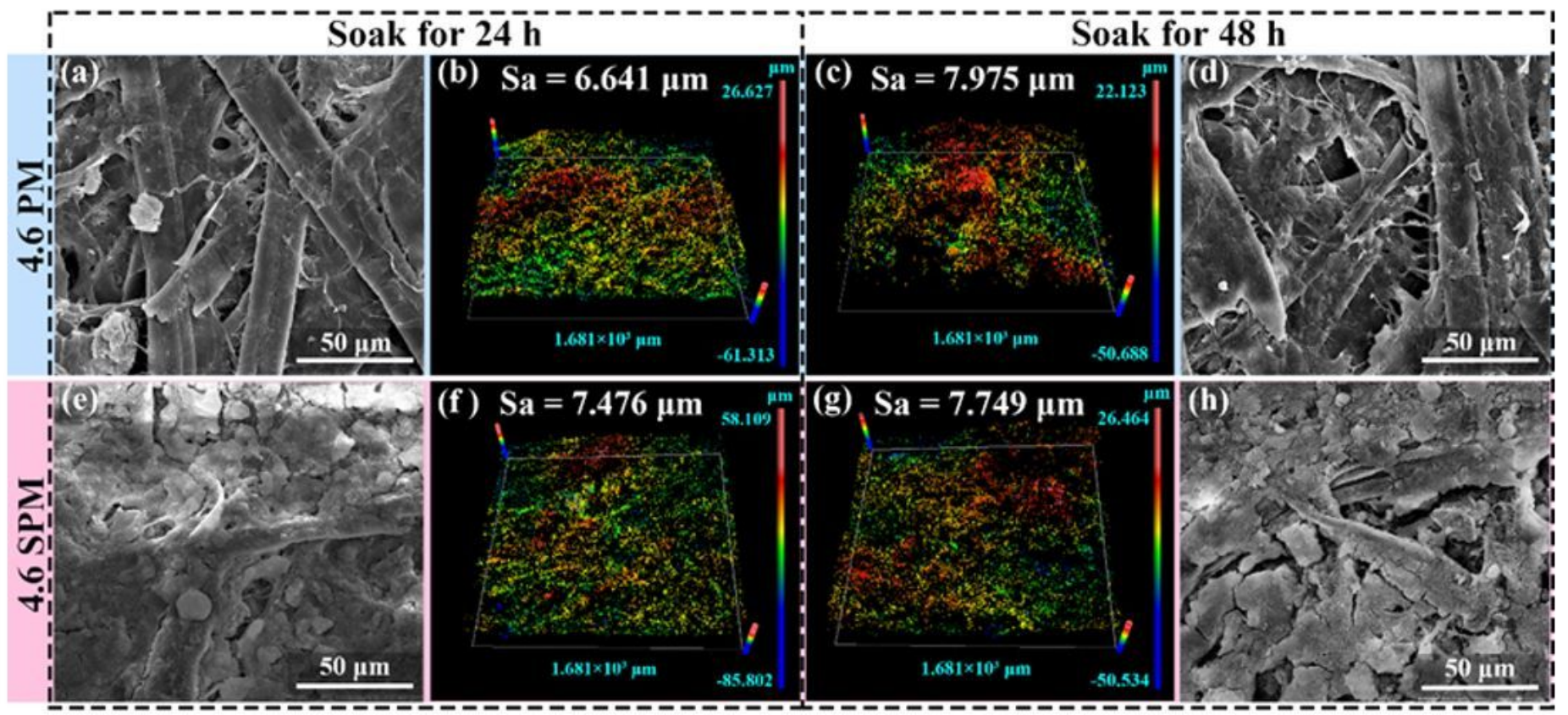

\section{Figure 6}

Original paper mulch (4.6 PM) soaked in $\mathrm{H} 2 \mathrm{SO} 4$ with a pH of 4.6 for 24 hours (a) 2000 times SEM image, (b) surface roughness image. The original paper mulch (4.6 PM) soaked in $\mathrm{H} 2 \mathrm{SO} 4$ with a pH of 4.6 for 48 hours (c) 2000 times SEM image, (d) surface roughness image. The SiO2/paper mulch (4.6 SPM) soaked in $\mathrm{H} 2 \mathrm{SO} 4$ with a pH of 4.6 for 24 hours (e) 2000 times SEM image, (f) surface roughness. SiO2/paper mulch (4.6 SPM) soaked in $\mathrm{H} 2 \mathrm{SO} 4$ with a pH of 4.6 for 48 hours (g) 2000 times SEM image, (h) surface roughness image. 


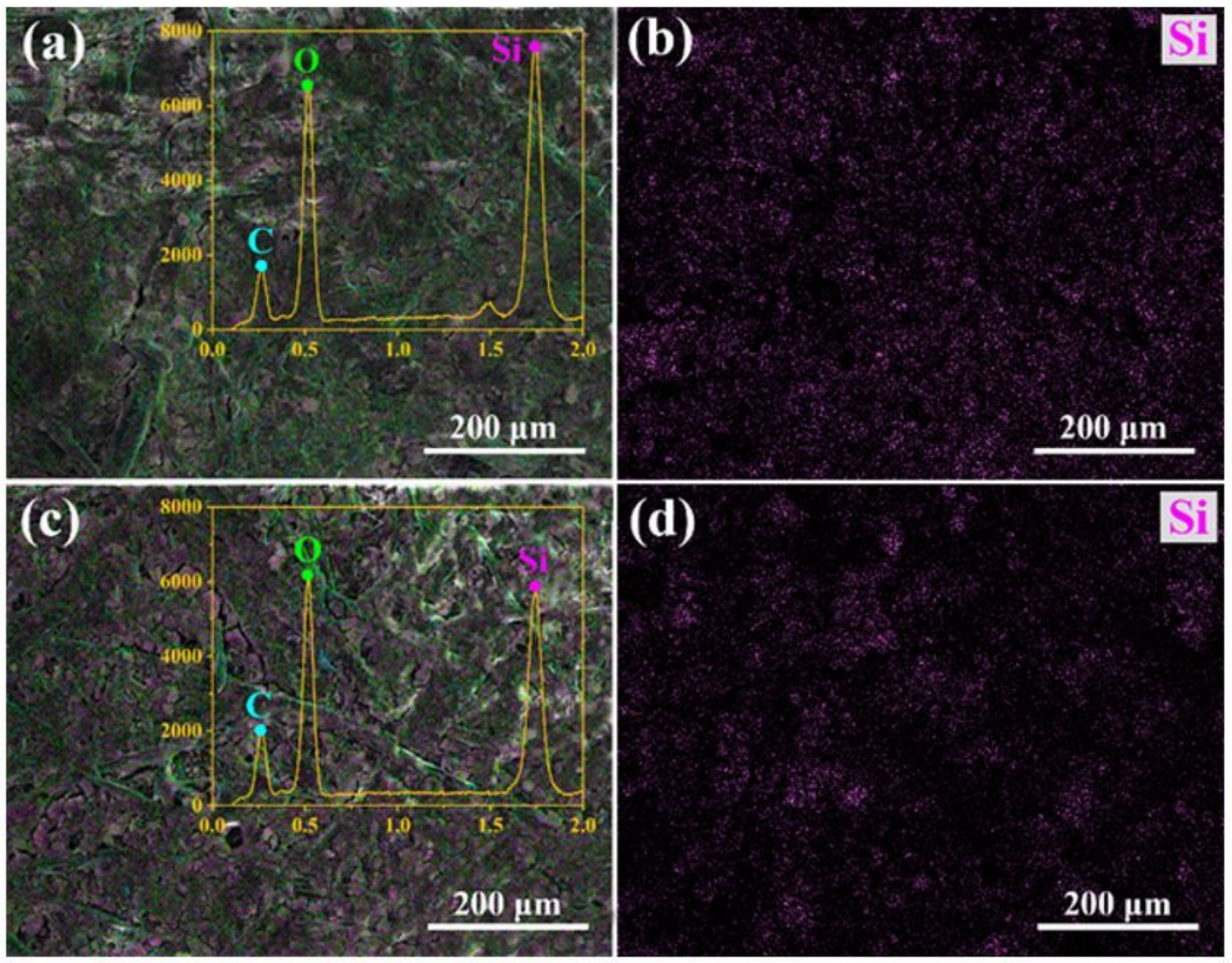

Figure 7

The surface of SiO2/paper mulch (4.6 SPM) soaked in $\mathrm{H} 2 \mathrm{SO} 4$ with $\mathrm{pH} 4.6$ for 24 hours (a) EDS element distribution diagram, (b) Si element distribution diagram; soaked in $\mathrm{H} 2 \mathrm{SO} 4 \mathrm{pH} 4.6$ for 48 hours SiO2/paper mulch (4.6 SPM) surface (c) EDS element distribution map, (d) Si element distribution map. 


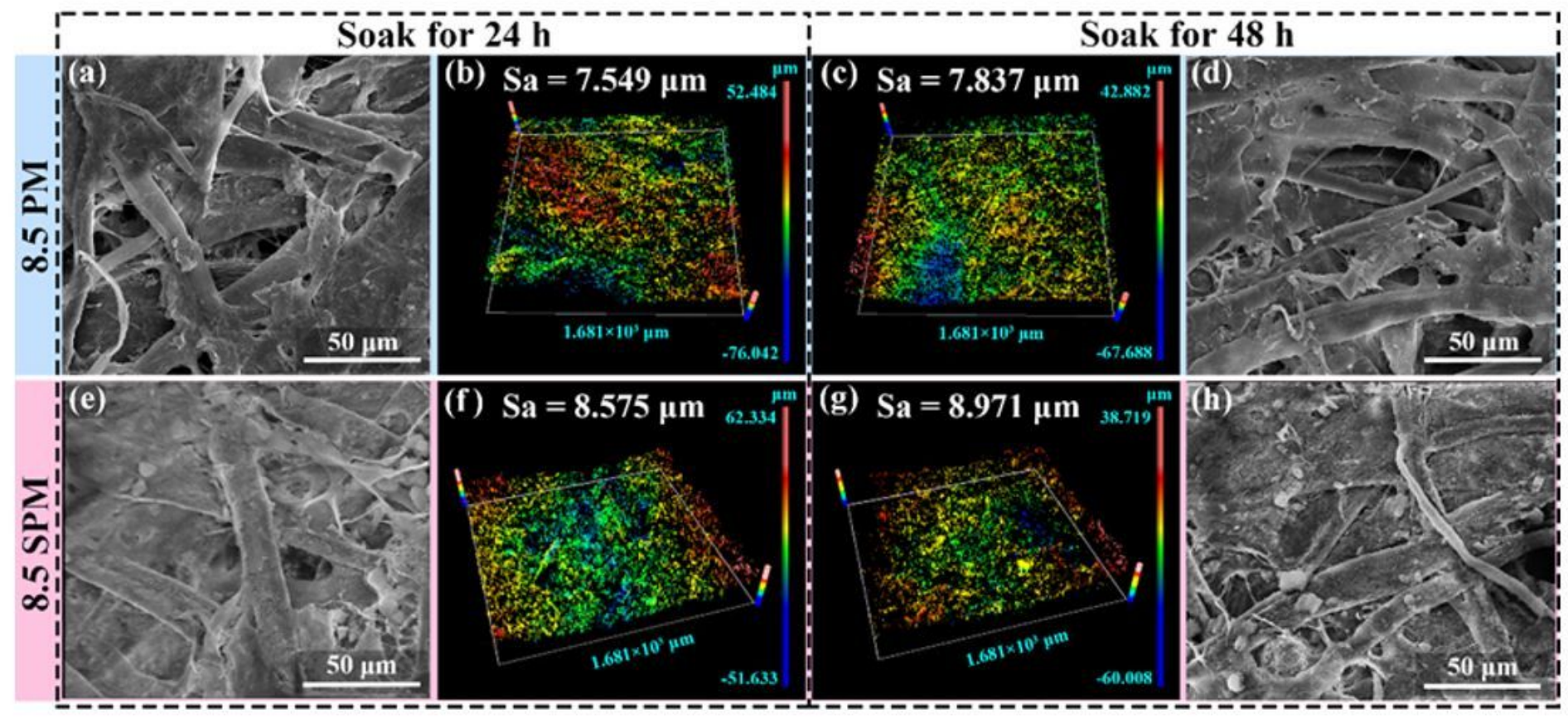

Figure 8

Original paper mulch (8.5 PM) soaked in $\mathrm{NaOH}$ with pH 8.5 for 24 hours (a) 2000 times SEM image, (b) surface roughness image. The original paper mulch film (8.5 PM) soaked in $\mathrm{NaOH}$ with a pH of 8.5 for 48 hours (c) 2000 times SEM image, (d) surface roughness image. SiO2/paper mulch film (8.5 SPM) soaked in $\mathrm{NaOH}$ with pH 8.5 for 24 hours (e) 2000 times SEM image, (f) surface roughness image. SiO2/paper mulch film (8.5 SPM) soaked in $\mathrm{NaOH}$ with pH 8.5 for 48h (g) 2000 times SEM image, (h) surface roughness image. 


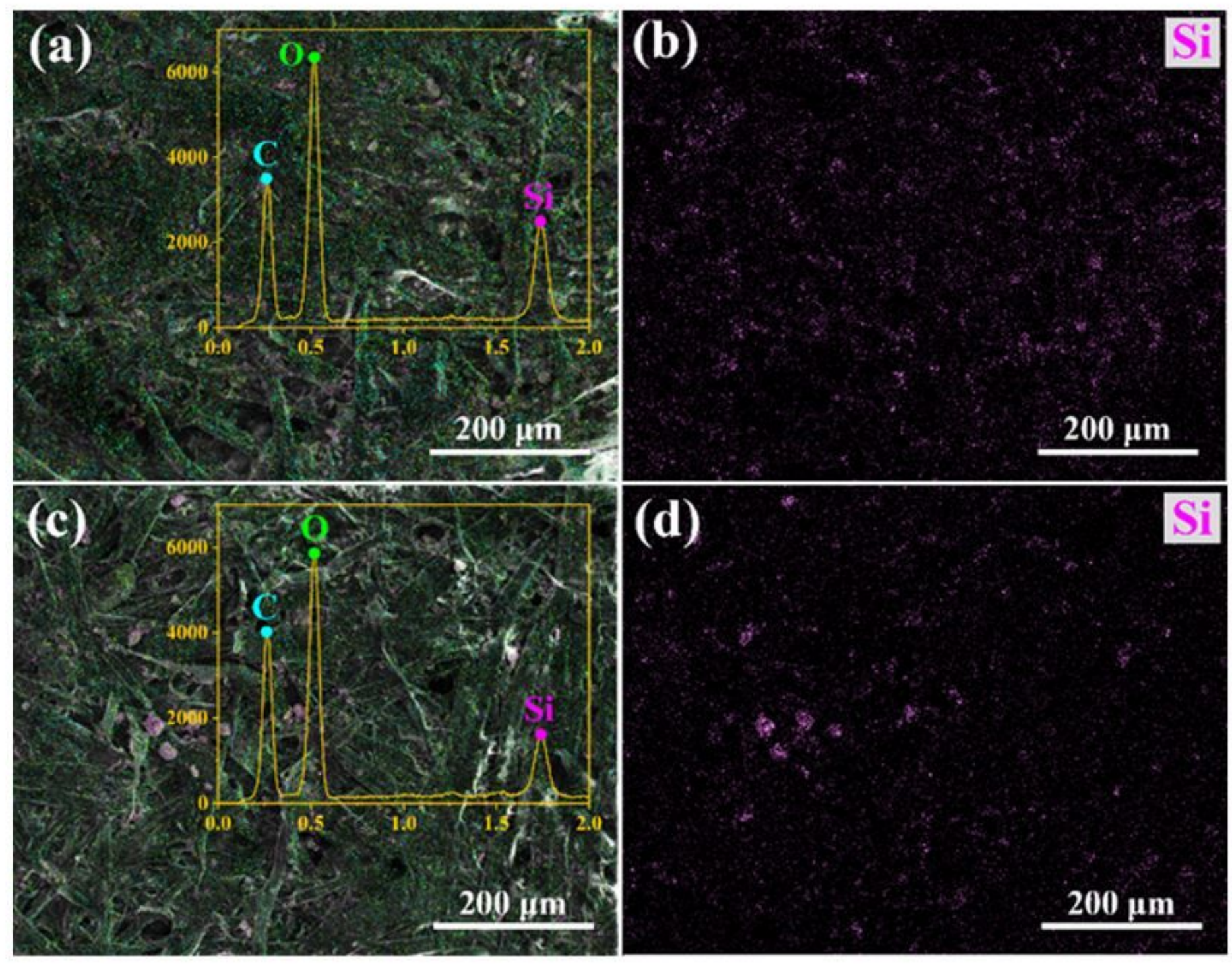

\section{Figure 9}

The surface of SiO2/paper mulch (8.5 SPM) after immersing in $\mathrm{NaOH}$ with a pH of 8.5 for 24 hours (a) EDS element distribution diagram, (b) Si element distribution diagram. The surface of SiO2/paper mulch (8.5 SPM) after immersing in $\mathrm{NaOH}$ with a $\mathrm{pH}$ of 8.5 for 48 hours (c) EDS element distribution diagram, (d) Si element distribution diagram. 

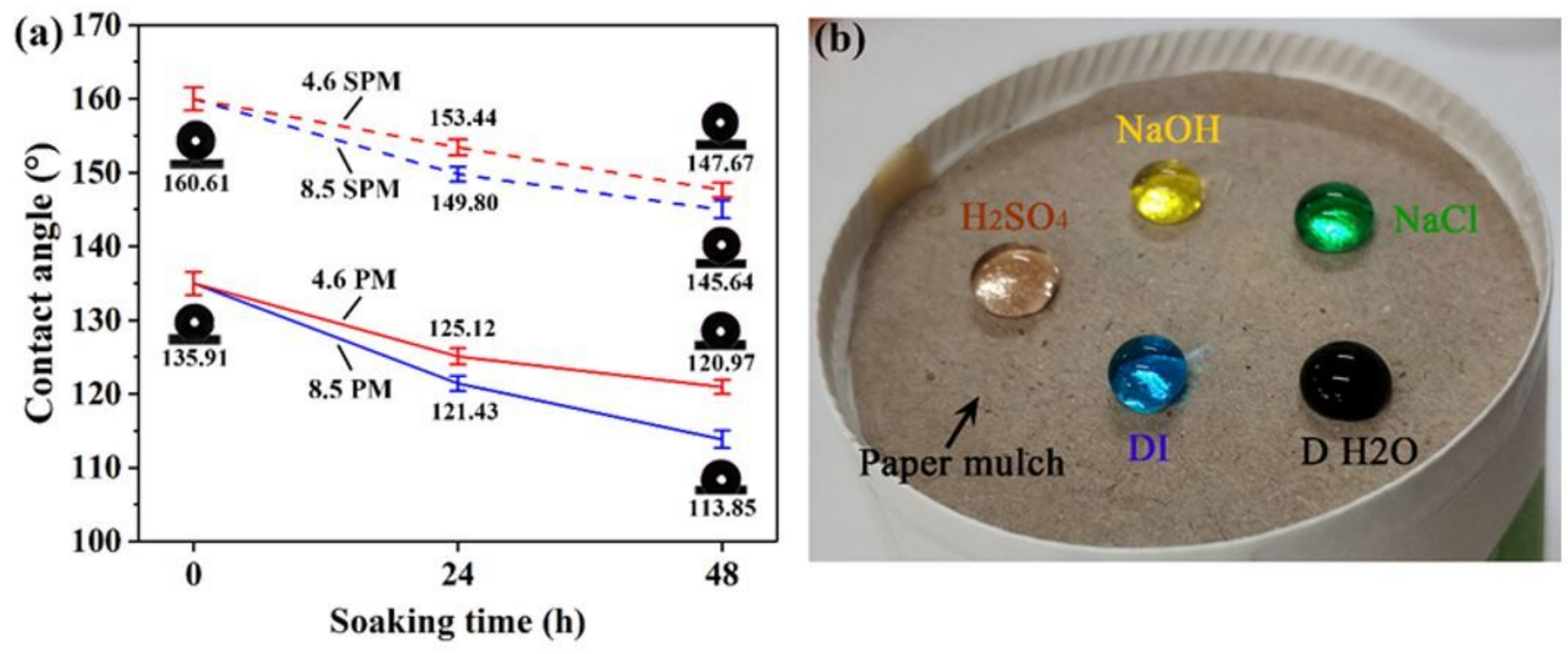

Figure 10

(a) Trend graph of contact angle change of paper mulch after soaking in acidic and alkaline solutions for different time. (b) The state of different droplets of acid, alkali and salt on the paper mulch. 

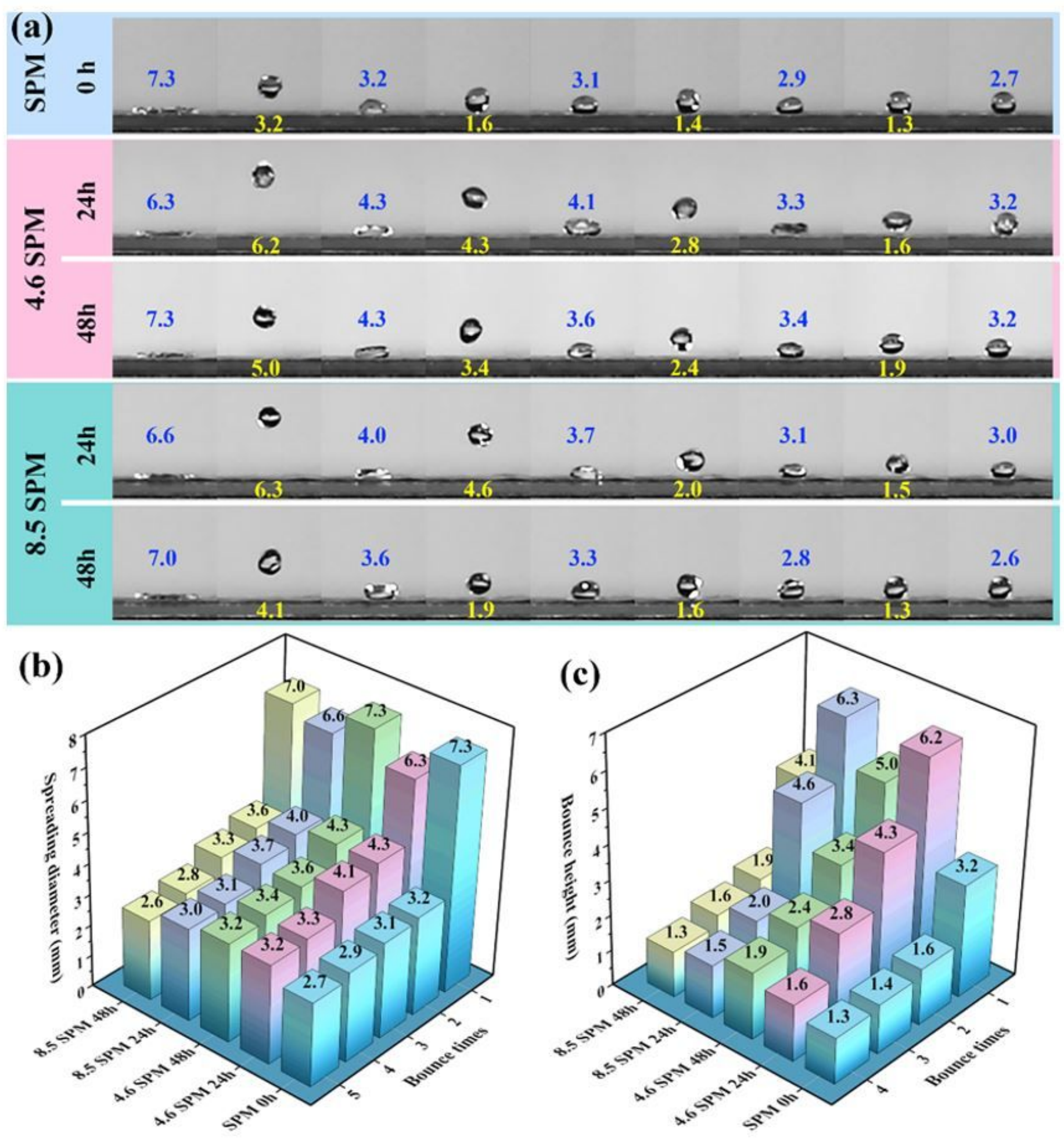

\section{Figure 11}

(a) The bouncing behavior of SiO2/paper mulch (SPM), 4.6 SPM and 8.5 SPM immersed for 24h and 48h. (B) SiO2/paper mulch (SPM), 4.6 SPM and 8.5 SPM soaked for $24 \mathrm{~h}$ and $48 \mathrm{~h}$, the spreading diameter histogram (c) SiO2/paper mulch (SPM), 4.6 SPM and 8.5 SPM soak for 24h and 48h The bounce height of multiple bounces. 

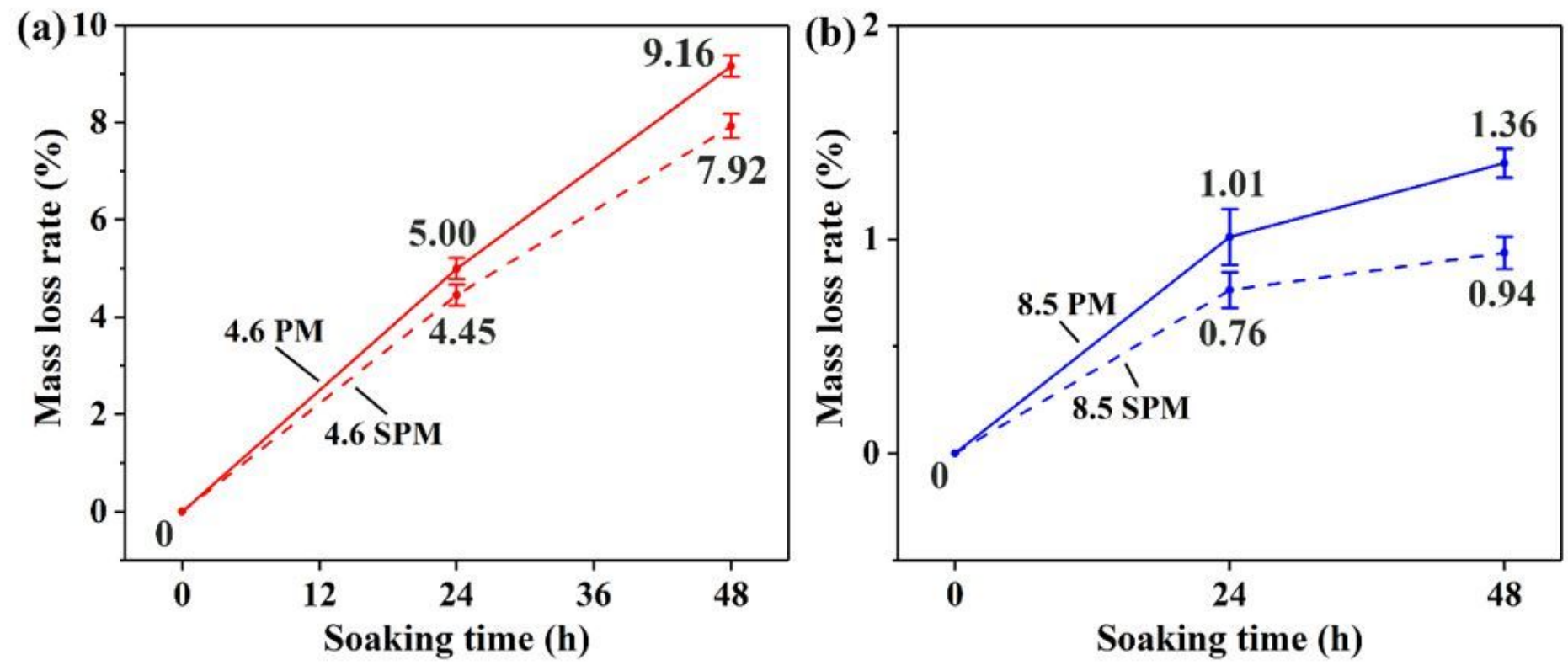

Figure 12

(a) The mass loss rate of original paper mulch and SiO2/paper mulch after soaking in acid solution. (b) The mass loss rate of original paper mulch and $\mathrm{SiO} 2 /$ paper mulch after soaking in alkaline solution
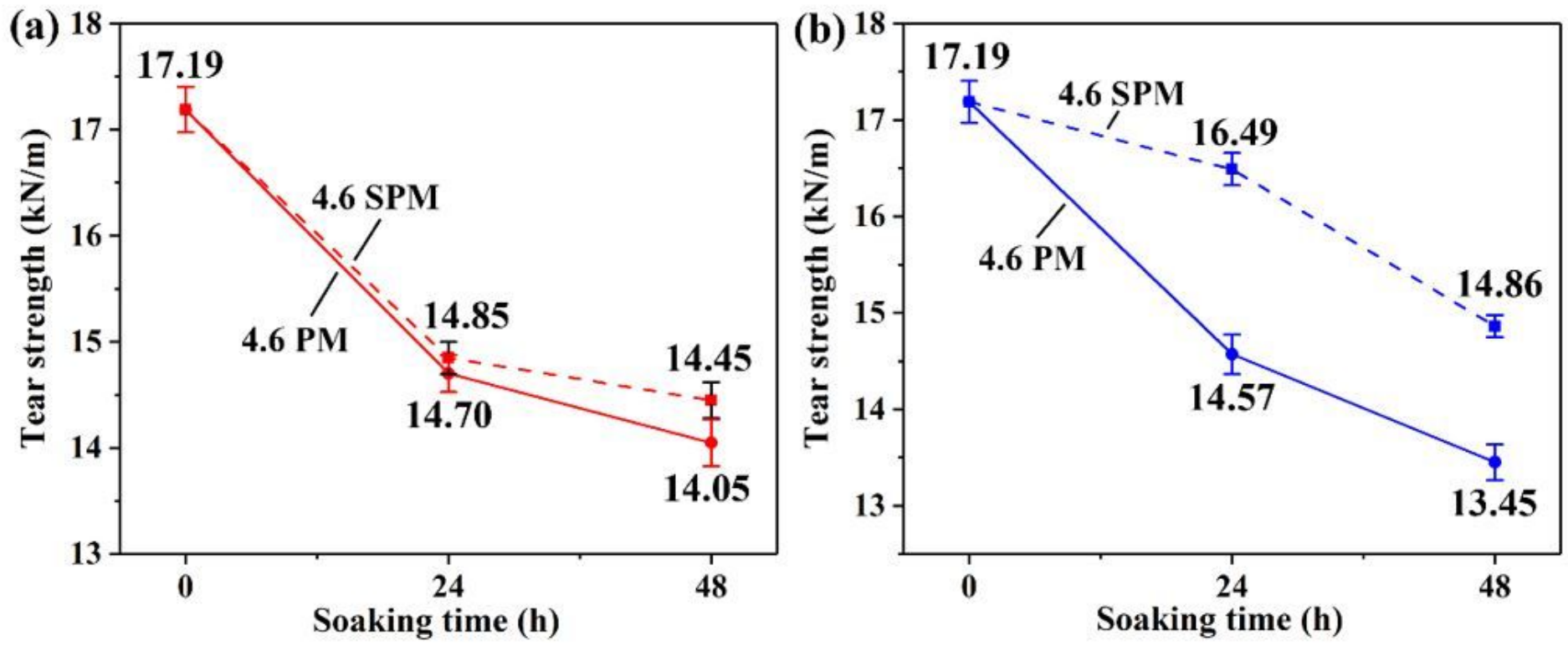

Figure 13

(a) The mass loss rate of original paper mulch and SiO2/paper mulch after soaking in acid solution. (b) The mass loss rate of original paper mulch and SiO2/paper mulch after soaking in alkaline solution 